\title{
Interactive comment on "Formation and sink of glyoxal and methylglyoxal in a polluted subtropical environment: observation-based photochemical analysis and impact evaluation" by Zhenhao Ling et al.
}

\section{Anonymous Referee \#2}

Received and published: 11 May 2020

The paper investigates the importance of glyoxal (GLY) and methylglyoxal (MGLY) on SOA formation in the PRD region. The importance of GLY and MGLY on the SOA formation has been previously studied but this study investigated several different methods of modeling GLY and MGLY SOA, which provides additional information on how to model this important process. I have a few suggestions for the authors when they revise their paper: 1 . The gas-phase concentrations of $\mathrm{OH} / \mathrm{HO} 2$ are not constrained in the box model simulations. Instead, they are calculated using the box model. However, GLY and MGLY can be removed in the gas phase reactions with $\mathrm{OH}$. Thus, it is 
necessary to evaluate the predicted $\mathrm{OH} / \mathrm{HO} 2$ concentrations to make sure the competing between gas/particle partitioning, which forms SOA, and the gas phase decay processes that reduce the SOA formation is correctly captured. 2. The impact of $\mathrm{O} 3$ on GLY and MGLY is not discussed. Looking at Figure 2, it is obvious that GLY and MGLY must decrease at night. GLY and MGLY can also react with O3. This is likely an import process that reduces GLY and MGLY at night, in addition to SOA formation from gas-to-particle partitioning and aqueous reactions. Since GLY and MGLY data are collected throughout the entire 24 hour period, it might be interesting to see how well the box model predicts GLY and MGLY at night with different SOA modeling approaches. The nighttime behavior of GLY and MGLY and their roles in SOA formation is not as clear as the daytime and should not be ignored in this study. 3 . The other issue that I think should be addressed is the primary emissions of GLY and MGLY, since not all are produced secondarily. It seems that no emissions of primary GLY and MGLY are included in the box model simulations. The authors might want to discuss how this omission can impact their conclusions. 4. Modeling SOA formation from GLY and MGLY using the Master Chemical Mechanism has been discussed in a more complete regional air quality model that considers the transport and emissions of GLY and MGLY ( $\mathrm{Li}$ et al. 2015). Another paper that discusses the importance of the GLY and MGLY on SOA formation is Ying et al 2015, which shows that including SOA from uptake of GLY/MGLY leads to significant improvement in predicated SOA in these southeast United Stated. These references appear to be neglected by the authors.

Li, J., Cleveland, M., Ziemba, L. D., Griffin, R. J., Barsanti, K. C., Pankow, J. F., and Ying, Q.: Modeling regional secondary organic aerosol using the Master Chemical Mechanism, Atmospheric Environment, 102, 52-61, 2015.

Ying, Q., Li, J., and Kota, S. H.: Significant Contributions of Isoprene to Summertime Secondary Organic Aerosol in Eastern United States, Environmental Science and Technology, 49, 7834-7842, 2015.

Printer-friendly version

Discussion paper
Interactive

comment 
Interactive comment on Atmos. Chem. Phys. Discuss., https://doi.org/10.5194/acp-2020-212, 2020.
ACPD

Interactive comment 